\title{
Acute and Steady-State Insulin Responses to Glucose in Nonobese Diabetic Subjects
}

\author{
Roger L. Lerner and Daniel Porte, Jr. \\ From the University of Washington School of Medicine and Veterans \\ Administration Hospital, Seattle, Washington 98108
}

A B S T R A C T Previous observations in normal subjects have suggested that when $5-g$ glucose pulses $(P)$ were given in the following sequence: before (P1) and 45 min after beginning a $300 \mathrm{mg} / \mathrm{min}$ glucose infusion (P2) ; during the 20th hr (P3) and $1 \mathrm{hr}$ after the infusion was stopped ( $\mathrm{P} 4)$; the insulin responses were consistent with a simple two-pool model. One pool is a readily available small storage pool which is refilled by a second, larger, more slowly responding pool that controls basal and steady-state insulin output. The identical protocol was employed to evaluate the insulin responses in 13 nonobese diabetic subjects.

Diabetics had basal insulin levels indistinguishable from normals (diabetics: $10.7 \pm 4$; normals: $10.7 \pm 5$, mean $\pm \mathrm{sD}, \mu \mathrm{U} / \mathrm{ml}$ ), but had significantly elevated basal glucose levels (diabetics: $161 \pm 27$; normals : $88 \pm 7, \mathrm{mg} /$ $100 \mathrm{ml}, P<0.05)$. The mean early insulin response (3-5 min $\Delta$ IRI) after a $5 \mathrm{~g}$ glucose pulse (P1) was significantly diminished in diabetics (diabetics $6.4 \pm 9$; normals : $32.5 \pm 14, \mu \mathrm{U} / \mathrm{ml}, P<0.01$ ) consistent with a defective storage pool output. The glucose disappearance rate, $K_{a}$, decreased in parallel with the early insulin response and the slope of the regression line between these two variables was virtually identical with that calculated from 16 normal subjects. Similar to normal subjects, during the short glucose infusion, the acute insulin response to $\mathrm{P} 2$ was diminished in diabetics $(P<$ 0.02 ). In normal subjects after $20 \mathrm{hr}$ of infusion, the rapid insulin responses to $\mathrm{P} 3$ are restored to the preinfusion $\mathrm{P} 1$ values, and $1 \mathrm{hr}$ after the infusion was stopped, the responses to $\mathrm{P} 4$ are increased twofold $(P<0.001)$. Diabetics, however, demonstrated decreased

This work was presented in part at the Meeting of the American Federation for Clinical Research, May 1969, Atlantic City, N. J.

Dr. Lerner is the recipient of Research Fellowship AM 40872. Dr. Porte is the recipient of Research Career Development Award 1K4 AM 865.

Received for publication 3 September 1971 and in revised form 20 December 1971. early responses to $\mathrm{P} 3(P<0.001)$ and no increased response to $\mathrm{P} 4$.

In contrast to the diminished acute insulin responses to glucose pulses, diabetics have steady-state insulin levels after $20 \mathrm{hr}$ of glucose infusion similar to those of normal subjects (diabetics : $25.7 \pm 13$; normals : $32.5 \pm 14$, $\mu \mathrm{U} / \mathrm{ml}$ ). Thus both basal and steady-state insulin levels of diabetics were comparable with those of normal subjects, which suggest that although the rapid insulin response from the storage pool output is defective in diabetics, the more slowly responding pool is intact.

\section{INTRODUCTION}

In recent years it has become apparent that insulin secretion is not a simple linear function of the glucose concentration. Based on in vivo and in vitro studies, models have been designed to explain this complex relationship $(1,2)$. We have made observations in normal subjects using a combination of rapid intravenous glucose injections (pulses) and infusions which can be explained by a simple two-pool model (3). One functional pool responds relatively slowly to long-term changes in glucose metabolism and hence is considered to be related to insulin synthesis. This pool controls insulin secretion in both the basal (fasting) and steady state (i.e., during prolonged glucose infusions), and also refills a second, smaller, functional storage pool of insulin which responds rapidly to an abrupt increase in plasma glucose level. The same experimental design has been employed to evaluate the interrelations between glucose and insulin in subjects with diabetes mellitus.

\section{METHODS}

13 white diabetic males, ranging from 19 to $71 \mathrm{yr}$ of age, all weighing within $15 \%$ of ideal body weight according to the Metropolitan Life Insurance tables, were hospitalized on the Clinical Research Center of University Hospital. Eight subjects had fasting hyperglycemia (defined as greater than $115 \mathrm{mg} / 100 \mathrm{ml}$ plasma glucose after an overnight 
TABLE I

Plasma Glucose Concentration

\begin{tabular}{|c|c|c|c|c|c|c|c|c|c|c|c|c|c|}
\hline \multirow[b]{2}{*}{ Patient } & \multirow[b]{2}{*}{ Age } & \multirow[b]{2}{*}{ Basal* } & \multicolumn{2}{|c|}{ 1st pulse } & \multirow[b]{2}{*}{$\begin{array}{c}\text { Glucose } \\
\text { infusion } \\
45 \mathrm{~min}\end{array}$} & \multicolumn{2}{|c|}{ 2nd pulse } & \multirow[b]{2}{*}{$\begin{array}{c}\text { Glucose* } \\
\text { infusion } \\
20 \mathrm{hr}\end{array}$} & \multicolumn{2}{|c|}{ 3rd pulse } & \multirow[b]{2}{*}{$\begin{array}{c}60 \mathrm{~min} \\
\text { post- } \\
\text { infusion }\end{array}$} & \multicolumn{2}{|c|}{ 4th pulse } \\
\hline & & & $\begin{array}{c}3-5 \\
\min \Delta\end{array}$ & $\mathrm{K}_{\mathbf{a}}$ & & $\begin{array}{c}3-5 \\
\min \Delta\end{array}$ & $\mathbf{K}_{\mathbf{G}}$ & & $\begin{array}{c}3-5 \\
\min \Delta\end{array}$ & $\mathbf{K}_{\mathbf{G}}$ & & $\begin{array}{c}3-5 \\
\min \Delta\end{array}$ & $\mathbf{K}_{\mathbf{G}}$ \\
\hline & & $\begin{array}{c}m g / \\
100 m l\end{array}$ & $\begin{array}{c}m g / \\
100 \mathrm{ml}\end{array}$ & $\% / \min$ & $\begin{array}{c}m g / \\
100 m l\end{array}$ & $\begin{array}{c}m g / \\
100 m l\end{array}$ & $\% / \min$ & $\begin{array}{c}\mathrm{mg} / \\
100 \mathrm{ml}\end{array}$ & $\begin{array}{l}m g / \\
100 m l\end{array}$ & $\% / \min$ & $\begin{array}{l}m g / \\
100 m l\end{array}$ & $\begin{array}{l}m \mathrm{mg} / \\
100 \mathrm{ml}\end{array}$ & $\% / \min$ \\
\hline A. W. & 50 & 88.5 & 38.5 & -1.30 & 118 & 41.3 & 1.00 & 122 & 42.9 & -2.00 & 85 & 38.6 & -0.71 \\
\hline E. R. & 27 & 91.5 & 34.8 & -1.50 & 150 & 37.3 & 0.32 & 205 & 48.1 & -0.57 & 106 & 32.6 & -2.30 \\
\hline R. V. W. & 37 & 95 & 34.6 & -1.20 & 148 & 35 & -0.04 & 106 & 43.3 & -1.40 & 81 & 43.3 & -0.94 \\
\hline C. W. & 41 & 96.3 & 27 & -0.99 & 148 & 38.7 & -0.12 & 136 & 42 & 0.71 & 80 & 35 & -2.10 \\
\hline J. OB. & 47 & 104.0 & 27 & -1.28 & 150 & 37 & -0.71 & 157 & 35.3 & 1.04 & 95 & 24.3 & -2.30 \\
\hline G. M. & 71 & 116 & 33.5 & -0.74 & 190 & 30.3 & -0.94 & 278 & 26.5 & -0.25 & 196 & 32.6 & -1.10 \\
\hline D. D. & 23 & 124 & 35 & -1.36 & 192 & 48 & 0.51 & 321 & 31 & -0.35 & $172 \ddagger$ & 44 & -1.54 \\
\hline H. B. & 41 & 142 & 26.2 & -0.81 & 243 & 31 & -0.02 & 308 & 23.2 & -0.30 & $156 \ddagger$ & 31 & -1.70 \\
\hline H. H. & 20 & 156 & 33 & -0.62 & 232 & 44.7 & -0.48 & 325 & 17 & -0.41 & $202 \ddagger$ & 23.3 & -0.87 \\
\hline C. H. & 25 & 173 & 34 & -0.92 & 225 & 52.3 & 0.18 & 351 & 47 & -0.19 & $204 \ddagger$ & 38 & -1.29 \\
\hline H. C. & 18 & 185 & 26.5 & -0.28 & 189 & 34.3 & 0 & 244 & 36.5 & -0.44 & $152 \ddagger$ & 39.6 & -2.30 \\
\hline D. S. & 21 & 312 & 26.7 & -0.69 & 356 & 41 & -0.15 & 433 & 25 & -0.28 & $316 \ddagger$ & 54 & -0.55 \\
\hline G. McC. & 39 & 408 & 29.5 & -0.62 & 450 & 38 & 2.1 & 531 & 15 & -0.83 & $348 \ddagger$ & 19 & -0.90 \\
\hline Mean & & 161 & 31.3 & -0.95 & 215 & 39.1 & +0.27 & 271 & 33.3 & -0.40 & 169 & 35 & -1.43 \\
\hline SD & & 127 & 4 & 0.4 & 94 & 6 & 0.7 & 127 & 11 & 0.8 & 86 & 9 & 0.6 \\
\hline \multicolumn{14}{|c|}{ Previously reported normal subjects (3) } \\
\hline Mean & & 88 & 29.2 & -1.75 & 133 & 35.8 & +0.03 & 115.5 & 34 & -1.82 & 76.6 & 34.9 & -2.15 \\
\hline SD & & 7 & 7 & 0.3 & 17 & 7 & 0.6 & 15 & 11 & 1 & 8 & 7 & 0.8 \\
\hline
\end{tabular}

* Mean of four samples.

$\ddagger 120$ min postinfusion.

fast), five subjects had abnormal oral glucose tolerance tests (4). ${ }^{1}$ No subject had ever received insulin. Those receiving any oral hypoglycemic medication before study discontinued it for at least 7 days before the test. All were encouraged to eat a weight-maintaining diet with at least $40 \%$ of calories as carbohydrate.

The experimental protocol outlined below is with minor exceptions identical with that previously reported for normal subjects (3) and the data from these eight normal subjects are compared with those from the diabetic subjects in this report. After a $12 \mathrm{hr}$ overnight fast, four basal (fasting) blood samples were obtained for measurements of glucose and insulin during a $60 \mathrm{~min}$ control period on the 1st day of the study. A $5 \mathrm{~g}$ glucose pulse $(\mathrm{P} 1)^{2}$ was administered as previously described (3) and $60 \mathrm{~min}$ later, a $300 \mathrm{mg} / \mathrm{min}$ glucose infusion was started. After $45 \mathrm{~min}$ of the infusion, a second $5 \mathrm{~g}$ glucose pulse (P2) was given. The infusion was continued overnight and the subjects ate lunch and dinner. At approximately 8 a.m. of the 2 nd day, four blood samples for steady-state glucose and insulin levels were obtained during a period of $60 \mathrm{~min}$. A third $5 \mathrm{~g}$ glucose pulse (P3) was given and

${ }^{1}$ Detailed information of height, weight, per cent ideal body weight, in all subjects and the results of the oral glucose tolerance tests in the five normoglycemic subjects is available from National Auxillary Publications Service.

${ }^{2}$ Abbreviations used in this paper: IRI, serum immunoreactive insulin; $K_{G}$, glucose disappearance rate; $P 1, P 2$, P3, P4, 5-g glucose pulses; $\Delta$, incremental change.
$60 \mathrm{~min}$ later the glucose infusion was discontinued. If glycosuria was present during the control period of the 2nd day, the interval between the cessation of the infusion and the fourth $5 \mathrm{~g}$ glucose pulse (P4) was $120 \mathrm{~min}$; if it was absent only $60 \mathrm{~min}$ were allowed to elapse. Data obtained from 16 nonobese normal subjects given $5-\mathrm{g}$ glucose pulses (5) were used to compare the early insulin response and the glucose disappearance rate (vide infra).

The protocol employed for obtaining timed blood samples and the methods for measuring plasma glucose and serum immunoreactive insulin (IRI) have been previously described $(3,6)$. The early insulin response $(3-5 \mathrm{~min} \Delta$ IRI $\mu \mathrm{U} / \mathrm{ml})$, the total incremental insulin output $(\mu \mathrm{U} \cdot \mathrm{min} / \mathrm{ml})$, and glucose disappearance rate $\left(K_{G}\right)$ were calculated by the same methods as previously reported for normal subjects (3).

\section{RESULTS}

Basal plasma glucose and serum insulin levels. Compared with the mean value of eight previously reported normal subjects, the mean basal plasma glucose level of all diabetics (Table I) was significantly greater $(P<0.05)$. In contrast to the wide range of basal glucose values (Table I), the mean basal insulin level in diabetic subjects was indistinguishable from normal subjects ( $\mathrm{Ta}$ ble II). There was no correlation in the basal state 
TABLE II

Serum Immunoreactive Insulin (IRI) Concentration

\begin{tabular}{|c|c|c|c|c|c|c|c|c|c|c|c|c|}
\hline \multirow[b]{2}{*}{ Patient } & \multirow[b]{2}{*}{ Basal* } & \multicolumn{2}{|c|}{ 1st pulse } & \multirow[b]{2}{*}{$\begin{array}{l}\text { Glucose } \\
\text { infusion } \\
\mathbf{4 5} \mathrm{min}\end{array}$} & \multicolumn{2}{|c|}{ 2nd pulse } & \multirow[b]{2}{*}{$\begin{array}{c}\text { Glucose* } \\
\text { infusion } \\
20 \mathrm{hr}\end{array}$} & \multicolumn{2}{|c|}{ 3rd pulse } & \multirow[b]{2}{*}{$\begin{array}{c}60 \mathrm{~min} \\
\text { post- } \\
\text { infusion }\end{array}$} & \multicolumn{2}{|c|}{ 4th pulse } \\
\hline & & $\begin{array}{c}3-5 \\
\min \Delta\end{array}$ & $\begin{array}{c}60 \mathrm{~min} \\
\text { area }\end{array}$ & & $\begin{array}{c}3-5 \\
\min \Delta\end{array}$ & $\begin{array}{c}30 \mathrm{~min} \\
\text { area }\end{array}$ & & 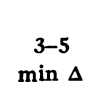 & $\begin{array}{c}60 \mathrm{~min} \\
\text { area }\end{array}$ & & $\stackrel{3-5}{\min \Delta}$ & $\begin{array}{c}\text { Co min } \\
\text { area }\end{array}$ \\
\hline & $\mu U / m l$ & $\mu U / m l$ & $\mu U \cdot \min / m l$ & $\mu U / m l$ & $\mu U / m l$ & $\mu U \cdot \min / m l$ & $\mu U / m l$ & $\mu U / m l$ & $\mu U \cdot \min / m l$ & $\mu U / m l$ & $\mu U / m l$ & $\mu U \cdot \min / m$ \\
\hline A. $W$. & 9.3 & 10.4 & 114 & 14 & 4.3 & 54 & 15.5 & 6.8 & 342 & 11 & 29 & 188 \\
\hline E. R. & 7.5 & 8.8 & 85.5 & 19 & -0.7 & 0 & 27.5 & 0.8 & 1.5 & 25 & 7.3 & 51.5 \\
\hline R. V. W. & 19.8 & 27.5 & 192 & 26 & 8 & 202 & 28.3 & 20.7 & 510 & 23 & 48 & 416 \\
\hline C. W. & 19.5 & 12.5 & 351 & 44 & 11 & 368 & 48.8 & -2.1 & 1130 & 30 & 39.7 & 295 \\
\hline J. OB. & 6.3 & 21.3 & 280 & 8 & 6.2 & 343 & 18 & 9.1 & 290 & 8 & 18.2 & 299 \\
\hline G. M. & 11.8 & 0.9 & 145 & 15 & -0.3 & 85 & 46.3 & -2.3 & 367 & 46 & 8.3 & 73.4 \\
\hline D. D. & 7.3 & 1.7 & 138 & 12 & -2.7 & 29 & 22.7 & -4.5 & 9.8 & $19 \ddagger$ & 0.8 & 257 \\
\hline H. B. & 11.1 & 1.5 & 8.5 & 9 & 1.0 & 76.7 & 20.3 & -1.3 & 73.1 & $13 \ddagger$ & 0.3 & 76 \\
\hline M. H. & 8.8 & -0.3 & 22.9 & 11 & -0.7 & 33.5 & 29.5 & -8.8 & 7.5 & $29 \ddagger$ & -3.3 & 201 \\
\hline C. $\mathrm{H}$. & 8.8 & -0.5 & 45.9 & 11 & -1.0 & 28.5 & 11.5 & -3.2 & 139 & $16 \ddagger$ & -5 & 0 \\
\hline H. C. & 12.3 & -0.8 & 15.6 & 12 & -0.7 & 91 & 42 & -7.3 & 67.5 & $47 \ddagger$ & -5.5 & 39.1 \\
\hline D. S. & 9.3 & -0.3 & 21.3 & 11 & -4.3 & 0 & 11.5 & -1.8 & 12.5 & $13 \ddagger$ & -1.3 & 15 \\
\hline G. McC. & 7.3 & 0.4 & 10.4 & 7 & -0.3 & 15 & 12.3 & -2.3 & 5.6 & $15 \ddagger$ & -2.7 & 45 \\
\hline Mean & 10.7 & 6.4 & 110 & 15.3 & 1.4 & 102 & 25.7 & 0.3 & 227 & 22.7 & 9 & 150 \\
\hline SD & 4 & 9 & 109 & 10 & 4 & 124 & 13 & 8 & 320 & 13 & 19 & 134 \\
\hline \multicolumn{13}{|c|}{ Previously reported normal subjects (3) } \\
\hline Mean & 10.7 & 32.3 & 270 & 25.5 & 15.1 & 203 & 32.5 & 38.2 & 636 & 17.6 & 56.3 & 446 \\
\hline SD & 5 & 14 & 169 & 13 & 17 & 143 & 27 & 22 & 239 & 4 & 35 & 212 \\
\hline
\end{tabular}

* Mean of four samples.

$¥ 120$ min postinfusion.

between plasma glucose and insulin levels in either the normal or diabetic group or both groups taken together.

Insulin responses to the first $5 \mathrm{~g}$ glucose pulse (P1).

After rapid injection of the first $5 \mathrm{~g}$ glucose bolus, (P1), the peak plasma glucose levels occurred between 3-5 min (Fig. 1). For each diabetic subject and for the entire diabetic group, the incremental change $(\Delta)$ in plasma glucose measured as the mean of the 3 through 5 -min glucose values above basal, was relatively con- stant after all four glucose pulses (Table I). The individual differences in the 3-5 min incremental $(\Delta)$ plasma glucose level appeared to reflect the differences in height and weight among the subjects. No significant differences in the 3-5 $\min \Delta$ glucose level were found between diabetic group and previously reported normal subjects (Table I).

Similar to normal subjects, those diabetic subjects whose insulin output increased after P1 also had a peak

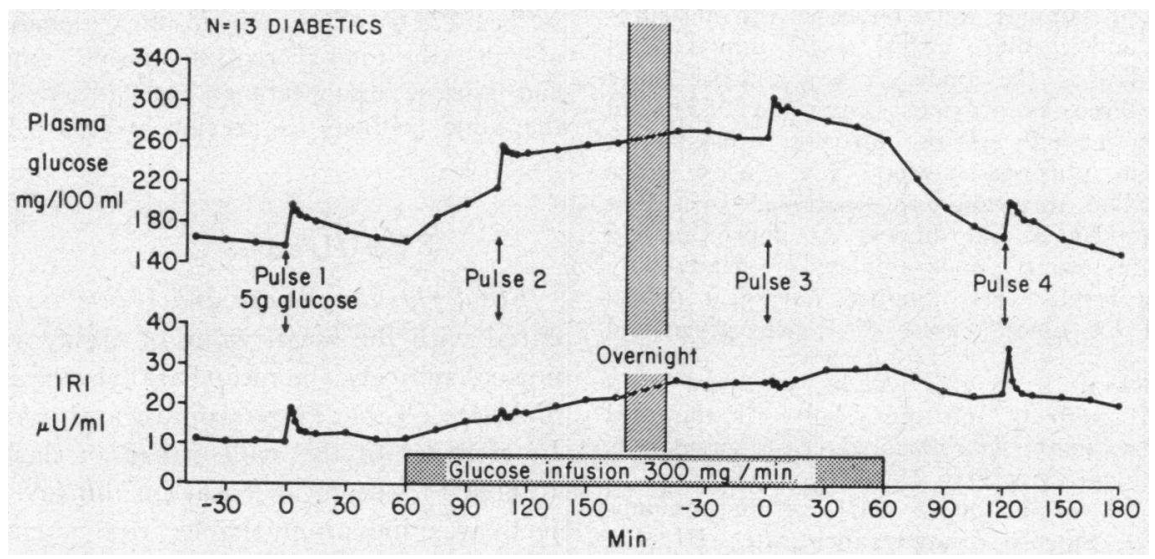

Figure 1 Mean glucose and insulin levels in all diabetic subjects. 
insulin response between 3 and $5 \mathrm{~min}$. The magnitude of the response at this time was quite variable, ranging from small negative deflections (Table II), to a response in one subject (R. V. W.) which was comparable with that observed in normal subjects (3). The mean early insulin response of the diabetics was, however, severely decreased $(P<0.01)$ compared with normal subjects (Table II). Diabetics subjects without fasting hyperglycemia had rapid insulin responses which overlapped the responses of their nondiabetic counterparts; however, those with fasting hyperglycemia had virtually absent early responses (Fig. 2). The mean total incremental insulin output to glucose $\mathrm{P} 1$ was significantly less than that observed in normal subjects $(P<0.02)$.

The mean $K_{\mathbf{G}}$, (Table I) was significantly less in the diabetic group than that of normals $(P<0.001)$. Diabetic subjects exhibited a linear correlation between the acute insulin response and $\mathrm{K}_{a}(r=+0.60, P<$ 0.05 , Fig. 3). A similar correlation has been observed in 16 other normal subjects (5) given the identical glucose pulse $(r=+0.66, P<0.01)$; the equations for the regression lines of both groups are almost identical: 13 diabetics: $y=0.02 x+0.78 ; 16$ normals: $y=0.02$ $x+0.79$. No significant correlation was observed between the total insulin responses and $\mathrm{K}_{\mathbf{6}}$ in either 16 normal subjects or 13 diabetic subjects comprising the present study.

Insulin responses during a short glucose infusion and to glucose pulse, $P 2$. In normal subjects, a $45 \mathrm{~min}, 300$ $\mathrm{mg} / \mathrm{min}$ glucose infusion was asociated with a $2 \frac{1}{2}$-fold increase in insulin levels $(P<0.01$, Table II). This output appeared to result from release from a small storage pool of insulin, since the acute insulin response to the same glucose pulse (P2) at this time was significantly

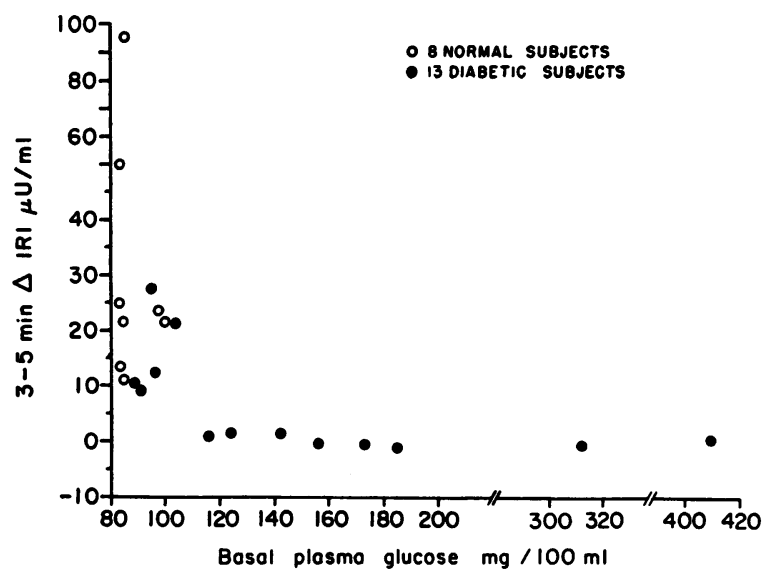

FIGURE 2 Relation between basal glucose levels and the acute insulin responses to glucose pulse (P1) in eight previously reported normal subjects (3) and all diabetic subjects. Note that each glucose and insulin value is the mean of four samples.

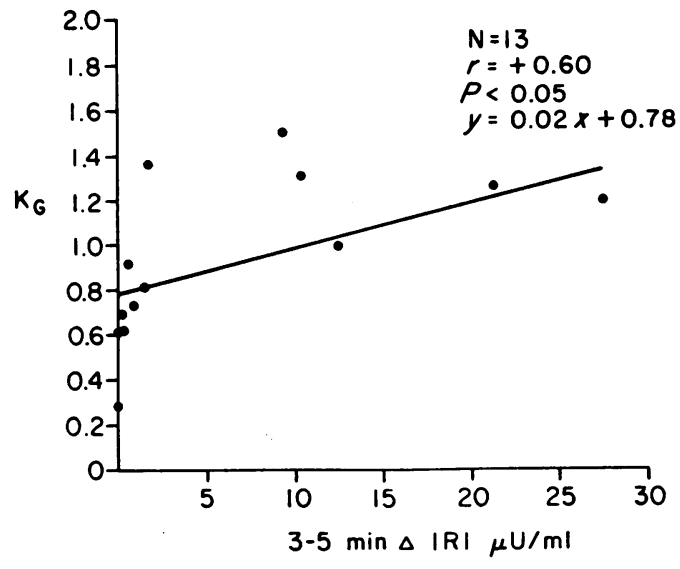

Figure 3 Relation between the acute insulin response and glucose disappearance rate $\left(K_{G}\right)$ in all diabetic subjects. Note that the $K_{G}$ values are positive in sign.

decreased $(P<0.001)$ by $58 \%$ (3). Diabetic subjects exhibited only a $1 \frac{1}{2}$-fold increase above basal insulin levels during the short glucose infusion $(P<0.05$, Table II). While serum insulin levels in diabetics were comparable with normal subjects at the start of the infusion, the increase after $45 \mathrm{~min}$ of a glucose infusion was less than in normal subjects, but only of borderline statistical significance $(P<0.1)$. Similar to normal subjects, diabetics had both decreased rapid insulin responses (Table II, $P<0.02$ ) and slower glucose disappearance rates (Table I, $P<0.001$ ) compared with the same parameters after $P 1$. The acute insulin responses to glucose P2 were less than in normal subjects (Table II, $P<0.02)$.

Effect of a prolonged glucose infusion on steady-state insulin levels and insulin responses to glucose pulses (P3 and P4). Steady-state insulin levels after $20 \mathrm{hr}$ of a $300-\mathrm{mg} / \mathrm{min}$ glucose infusion were increased $(P<$ 0.001 ) in all diabetic subjects compared with basal insulin levels (Fig. 4). Although the mean steady-state insulin response was slightly lower than that of normal subjects (Table II), this difference was not statistically significant $(P=0.4)$. The mean incremental $(\Delta)$ increase in steady-state insulin levels above basal values was also slightly but not significantly lower than that of normal subjects ( $\Delta$ increase : diabetics: $15 \pm 11$; normals : $22 \pm 10, \mu \mathrm{U} / \mathrm{ml}$, mean $\pm \mathrm{SD}, P<0.2)$. Furthermore, subjects with the worst carbohydrate tolerance (or highest basal glucose levels) had just as large incremental or absolute insulin increase after $20 \mathrm{hr}$ glucose infusion as those with the mildest impairment (Tables I and II). However, the mean steady-state glucose level was significantly higher in diabetics (Table I, $P<0.01$ ), as was the incremental $(\Delta)$ increase in steady-state glucose levels above basal values ( $\Delta$ increase: diabetics: $110 \pm$ 61 ; normals : $27.6 \pm 15 \mathrm{mg} / 100 \mathrm{ml}, P<0.001)$. 


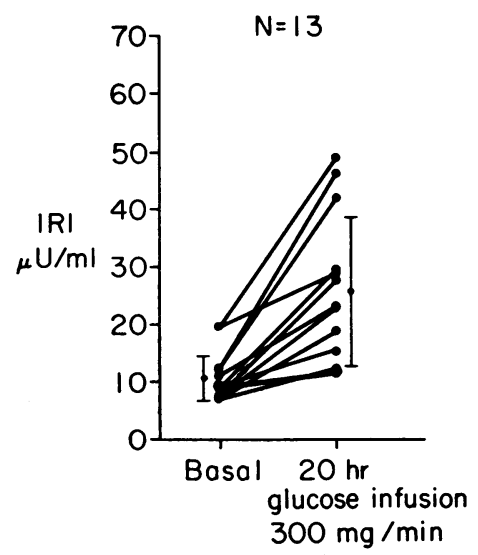

Figure 4 Basal and steady-state insulin levels in all diabetic subjects. Note that each insulin value is the mean of four samples.

In normal subjects during the prolonged infusion, the acute insulin response to $\mathrm{P} 3$ was restored compared with the response to the preinfusion pulse (P1) and was increased $(P<0.001)$, compared with the response to $P 2$. In contrast, the early insulin responses to $\mathrm{P} 3$ in all diabetics remained significantly diminished $(P<0.001)$ compared with either the preinfusion pulse $(\mathrm{P} 1)$ or to the response of normal subjects to the third glucose pulse $(P<0.001)$, and in fact $\mathrm{P} 3$ responses were not significantly different than to $\mathrm{P} 2$ (Table II).

A period of 120 min was allowed between cessation of the glucose infusion and administration of the fourth glucose pulse (P4) in all subjects with glycosuria except G. M. (Table I) on the 2 nd day of the study. The remaining six subjects received the fourth glucose pulse (P4) as normal subjects did, $60 \mathrm{~min}$ after cessation of the infusion. Although mean plasma glucose levels were not elevated either at 60 or $120 \mathrm{~min}$ after stopping the infusion compared with basal values on the 1 st day (Table I), mean insulin levels at 60 and 120 min were elevated compared with basal insulin values at the start of the study (Table II, $P<0.01$ ). Compared with the output to $P 3$, the rapid insulin response to the final glucose pulse (P4) was significantly increased $(P<$ 0.05 ), but total insulin output was not significantly changed (Table II). The $\mathrm{K}_{\boldsymbol{G}}$ during $\mathrm{P} 4$ was not significantly increased compared with P1 (Table I). The acute insulin response to the final glucose pulse was slightly but not significantly increased (Table II) compared with P1 but was still significantly lower than normal subjects who uniformly had an increased insulin response to pulse $4(P<0.001)$.

\section{DISCUSSION}

The present study indicates as have others, that normal weight diabetic subjects have a variably decreased early insulin response and diminished glucose disappearance rate to intravenous glucose $(7,8)$. However, considerable overlap exists between the normal and the diabetic subjects in this study and it is not possible to segregate completely all individuals as either diabetic or normal on the basis of their insulin responses or glucose disappearance rates. Thus in the present study, there is a continuous spectrum of insulin responses and glucose disappearance rates after the injection of a small dose of glucose. These data are similar to those of Moorehouse, Steinberg, and Tessler, who using small glucose loads, observed significantly lowered mean $\mathrm{K}_{\mathrm{G}}$ values in diabetics but overlapping values with normal subjects (9). Since the regression equation defining the relationship between the acute insulin response and carbohydrate tolerance $\left(\mathrm{K}_{\mathbf{G}}\right)$ is essentially the same for normal and diabetic subjects, these nonobese diabetic subjects do not appear to have an altered sensitivity to endogenous insulin.

The variably decreased acute insulin responses found in these diabetic subjects are probably not due to the small glucose dose used, since larger glucose doses conventionally given (i.e., $20 \mathrm{~g}$ and greater), which are a maximally effective stimulus for acute insulin secretion in normal subjects (5), have also been shown to result in defective rapid output $(7,8)$. Therefore, it seems likely that the diabetic cannot secrete adequate amounts of insulin to an intravenous challenge to all glucose loads. The continuous administration of glucose for $20 \mathrm{hr}$ appears to exaggerate this defect and to magnify the differences between normal and diabetic subjects. Thus when $5 \mathrm{~g}$ of glucose were given after $20 \mathrm{hr}$ of glucose infusion (P3), all diabetic subjects showed either negative or markedly diminished acute insulin responses compared with the response to the first glucose pulse. Although most of the normal subjects exhibited the same or an increased acute insulin response to glucose pulse 3 , the response of some of the normal subjects also decreased (3), indicating an overlap between normals and diabetics in this parameter as well. In terms of the previously described two-pool model (3), these data are consistent with the concept that diabetic subjects are not able to maintain or refill the small functional storage pool of insulin available for immediate release as effectively as their normal counterparts.

It must be emphasized, however, that the present studies were all performed in normal weight diabetic subjects who are a distinct minority within the noninsulin requiring diabetic population. In our experience, at least $90 \%$ of noninsulin requiring diabetics are more than $15 \%$ above ideal body weight. The frequent concurrence of obesity and carbohydrate intolerance has been commented on previously (10-12). The selection of nonobese subjects for this study was made to avoid the influence 
of obesity on insulin secretion which often causes complexity in the interpretation of insulin levels (13). Nevertheless, it seems likely that the same relative defect in the small storage pool also exists in obese diabetic subjects (14).

The temporal relationships observed in normal subjects between the glucose challenge and the subsequent acute insulin response were identical with those seen in the diabetic subjects who were able to respond to glucose rapidly. Although the increments were usually smaller, the maximum insulin output occurred between 3 and $5 \mathrm{~min}$ after a rapid glucose injection. These observations suggest that the delay in insulin output which often appears during oral glucose tolerance test $(7,15)$ might be due to a defect in the output from the acutely releasable pool with more normal responses from other functional pools creating the impression of a delayed insulin secretory pattern. Those subjects who demonstrated no positive insulin increments after glucose pulse 1 were the same subjects who exhibited negative deflections during P3 and P4. Since the time at which the negative deflections occurred was identical with that for the insulin increment in normal subjects, it seems likely that these fluctuations represent an attempt of the islet to respond from a similar functional unit in diabetics to the glucose challenge. Thus, the lack of response in diabetics to P1 appears to represent a truly deficient early response.

The precise meaning of the negative insulin responses is not yet clear. The data of Seltzer, Allen, Herron, and Brennan (7) indicate a mean decreased insulin level 5 min after intravenous glucose in a group of nonobese diabetics with fasting hyperglycemia. Although none of the subjects in the present study showed this fall after the first $5 \mathrm{~g}$ pulse, we have also seen transient declines in insulin levels in several hyperglycemic nonobese diabetic subjects without the infusion of glucose after a 20 $g$ glucose pulse, ${ }^{3}$ a dose similar to that employed by Seltzer et al. (7). Thus the phenomenon does not appear to require a continuous glucose infusion for its demonstration. A possible reason why negative insulin responses have not been more commonly observed may be in part that blood samples for measurements of insulin are not usually obtained after a rapid injection of glucose during the earliest phases of insulin secretion, at which time this phenomenon is observed. The negative insulin responses after glucose could be due to rapid expansion of plasma volume secondary to the administration of $10 \mathrm{ml}$ of hypertonic $(50 \%)$ glucose solution. This could account for small (less than $1 \mu \mathrm{U} / \mathrm{ml}$ ) negative acute insulin responses seen in some of the diabetics. However, as illustrated by patient G. McC., whose acute response

\footnotetext{
${ }^{3}$ Unpublished observations.
}

was $-2.7 \mu \mathrm{U} / \mathrm{ml}$ to glucose pulse 4 (Table II), a negative response of this magnitude would require rapid expansion of the plasma volume of $575 \mathrm{ml}$, far in excess of the predicted $100 \mathrm{ml}$ increase in volume produced by the hypertonic glucose solution. An alternative explanation for the negative insulin responses seen in such patients might be that when the storage pool responds to an abrupt increase in the plasma glucose concentration, output from the more slowly responding or basal pool is simultaneously inhibited. Therefore only when the storage pool is nearly devoid of insulin would the transient fall due to inhibition of basal output be observed.

In contrast to the diminished acute insulin responses to the small glucose pulse, basal and steady-state insulin levels in diabetics were comparable with those in normal subjects. Although the mean steady-state insulin level was lower in diabetic subjects during the continuous glucose infusion, this was not significant and was not at all related to the magnitude of the hyperglycemia. For example, subject H.C., one of the most hyperglycemic subjects at the start of the study, had one of the largest increases in steady-state insulin levels after $20 \mathrm{hr}$ of glucose infusion. Furthermore, no differences were observed in both basal and steady-state insulin levels between those diabetic subjects with normal fasting plasma glucose levels and those with fasting hyperglycemia. These steady-state insulin levels, however, are maintained in the presence of continuous hyperglycemia which is significantly greater in diabetic than in normal subjects after the identical continuous glucose infusion, although again, some overlap is present in the mildest diabetic subjects. The greater degree of hyperglycemia with comparable steady-state insulin levels in diabetics might possibly be related to increased amounts of circulating proinsulin. Although proinsulin has not been measured during the steady-state condition of this study, proinsulin levels in the basal state and shortly after oral glucose in nonobese diabetic subjects have been reported to be similar to values in normal subjects $(16,17)$. Another possible explanation for the present observations is that the diabetics may have increased hepatic removal of insulin. Blackard and Nelson reported that in normal and diabetic subjects basal insulin levels were comparable in the portal and peripheral vein $(18,19)$. After an intravenous glucose load, portal and peripheral insulin levels were linearly correlated in both groups, which suggested that a constant fraction was removed by the liver. Furthermore, the correlation between portal and peripheral insulin levels was not significantly different in the normal and diabetic groups and the peripheral levels in those studies encompassed the steady-state insulin levels in the present study $(18,19)$. Thus it appears unlikely that increased hepatic insulin removal could explain the discrepancy between the steady-state 
glucose and insulin levels in the normal and diabetic subjects.

The present data suggest that the more slowly responding pool may be defective in diabetics, since their basal and steady-state insulin levels were comparable with those of normal subjects but at significantly greater levels of hyperglycemia. Normal subjects probably would have had proportionally higher basal steady-state insulin levels at the respective plasma glucose levels found in diabetics. The greater level of hyperglycemia may have provided the additional stimulus for the insulin response from the slowly responding pool such that after $20 \mathrm{hr}$ of glucose infusion their insulin levels were comparable with those of the normal subjects. Thus, diabetics were able to compensate for a defective slowly responding pool because of an increased plasma glucose concentration.

The assumption underlying the defective slowly responding pool hypothesis is that basal and steady-state insulin levels are linearly related to simultaneously measured plasma glucose levels. But when these two variables have been examined in the basal and steady state no such relationship was noted and several studies have shown a complete lack of correlation $(12,14,20)$. Furthermore, recent evidence suggests that insulin levels may be more related to other parameters of glucose metabolism. For example, Christensen and Orskov reported that human forearm glucose uptake and not simultaneously measured plasma glucose levels was highly correlated with the level of endogenously secreted insulin (21). Forbath and Hetenyi demonstrated that in the basal state glucose turnover was the same in normal and diabetic subjects even though the diabetic subjects had fasting hyperglycemia (22) and on the basis of the present study might be expected to have similar basal insulin levels. Thus, subjects with different plasma glucose levels and comparable basal insulin levels may still have the same rates of glucose turnover. If both normal and diabetic subjects had hepatic glucose output comparably suppressed by the prolonged glucose infusion, then glucose turnover after $20 \mathrm{hr}$ of such an infusion would be expected to be the same since both groups were being infused at the same rate. In this regard, it is of interest to note that Felig and Wahren (23) observed inhibition of splanchnic glucose output during glucose infusion at insulin levels very similar to those observed during the steady state in the present study. Thus, if the basal and steady-state insulin output from the more slowly responding pool is related to some parameter of glucose metabolism other than plasma glucose level, then insulin levels in diabetics under these conditions would indicate a normally functioning system.

The increased degree of hyperglycemia of the diabetic subjects may be related to the fact that they, like their nondiabetic counterparts, had both lunch and supper between glucose pulses 2 and 3. However, the diabetics were unable to respond adequately to these stimuli and thus the hyperglycemia in the following morning may be simply a reflection of the severity of their glucose intolerance. It is possible that even after $20 \mathrm{hr}$ of glucose infusion, these diabetics may not have been in a true steady state of hyperglycemia. Thus we would suggest that it is not necessary to conclude that insulin output is normal after $20 \mathrm{hr}$ of glucose infusion in these diabetic subjects simply as a result of the compensating effects of simultaneous hyperglycemia. In order to answer this question it is necessary to know the relationship between the output from the more slowly responding pool and the rate of continuous glucose administration in both normal and diabetic subjects in whom meal eating is prohibited. It is of interest that hyperglycemic diabetic subjects who are fasted for 3 days have been found to lower glucose levels more than normal subjects, thus eventually resulting in glucose values indistinguishable from normal subjects who are fasted for the same duration (24).

Nevertheless, even if output from the slowly responding pool is defective and has been completely compensated for by increased hyperglycemia, it is quite clear that the response to continuous glucose administration is qualitatively different from the response of the small storage pool to a rapid glucose challenge. The latter cannot be compensated for no matter how or in what combination glucose is given whereas even those diabetic subjects with no response to either a glucose pulse or short infusion, were able to respond normally with an increased steady-state output during prolonged glucose infusion. Clearly further investigation is necessary to define the output and the controlling factors from this more slowly responding insulin pool.

\section{ACKNOWLEDGMENTS}

The authors wish to thank Doctors Robert L. Nielsen and William J. Steenrod, Jr. of the Virginia Mason Clinic, Seattle, Washington, for the opportunity to study patients D. D. and J. OB.

This investigation was supported in part by U. S. Public Health Service research grant AM 12829, Training grant AM 05498, and the National Institutes of Health Research Center facility of University Hospital, (FR-37), Seattle, Washington.

\section{REFERENCES}

1. Curry, D. L., L. L. Bennett, and G. M. Grodsky. 1968. The dynamics of insulin secretion by the isolated perfused rat pancreas. Endocrinology. 83: 572.

2. Cerasi, E., and R. Luft. 1967. "What is inherited-what is added" hypothesis for pathogenesis of diabetes mellitus. Diabetes. $16: 615$.

3. Porte, D., Jr., and A. Pupo. 1969. Insulin responses to glucose: evidence for a two pool system in man. J. Clin. Invest. 48 : 2309. 
4. Wilkerson, H. L. C., H. Hyman, M. Kauffman, A. C. McCuistion, and J. O'S. Francis. 1960. Diagnostic evaluation of oral glucose tolerance tests in nondiabetic subjects after various levels of carbohydrate intake. N. Engl. J. Med. 262 : 1047.

5. Lerner, R. L., and D. Porte, Jr. 1971. Relationships between intravenous glucose loads, insulin responses, and glucose disappearance rates. J. Clin. Endocrinol. Metab. $33: 409$.

6. Morgan, C. R., and A. Lazarow. 1963. Immunoassay of insulin: two antibody system. Plasma levels of normal, subdiabetic and diabetic rats. Diabetes. 12: 115.

7. Seltzer, H. S., E. W. Allen, A. L. Herron, Jr., and M. T. Brennan. 1967. Insulin secretion in response to the glycemic stimulus: relation of the delayed initial release to carbohydrate tolerance in mild diabetes. $J$. Clin. Invest. $46: 323$.

8. Simpson, R. G., A. Benedetti, G. M. Grodsky, J. H. Karam, and P. H. Forsham. 1968. Early phase of insulin release. Diabetes. $17: 684$.

9. Moorehouse, J. A., J. Steinberg, and B. B. Tessler. 1963. Effect of glucose dose upon intravenous glucose tolerance in health and diabetes. J. Clin. Endocrinol. Metab. 23: 1074.

10. Karam, J. H., G. M. Grodsky, and P. H. Forsham. 1963. Excessive insulin response to glucose in obese subjects as measured by immunochemical assay. Diabetes. $12: 197$.

11. Perley, M., and D. M. Kipnis. 1966. Plasma insulin responses to glucose and tolbutamide of normal weight and obese diabetic and nondiabetic subjects. Diabetes. $15: 867$.

12. Crockford, P. M., W. R. Hazzard, and R. H. Williams. 1969. Insulin response to glucagon: the opposing effects of diabetes and obesity. Diabetes. 18: 216.

13. Porte, D., Jr., J. D. Bagdade, and E. L. Bierman. 1970. The critical role of obesity in the interpretation of serum insulin levels. In Early Diabetes. R. A. Camerini-Davalos, and H. S. Cole, editors. Academic Press, Inc., New York. 191.
14. Bagdade, J. D., E. L. Bierman, and D. Porte, Jr. 1967. The significance of basal insulin levels in the evaluation of the insulin response to glucose in diabetic and nondiabetic subjects. J. Clin. Invest. 46: 1549.

15. Yalow, R. S., and S. A. Berson. 1960. Immunoassay of endogenous plasma insulin in man. J. Clin. Invest. 39: 1157.

16. Gorden, P., and J. Roth. 1969. Plasma insulin: fluctuations in the "big" insulin component in man after glucose and other stimuli. J. Clin. Invest. 48: 2225.

17. Gorden, P., B. Sherman, and J. Roth. 1971. Proinsulinlike component of circulating insulin in the basal state and in patients and hamsters with islet cell tumors. $J$. Clin. Invest. 50: 2113.

18. Blackard, W. G., and N. C. Nelson. 1970. Portal and peripheral vein immunoreactive insulin concentrations before and after glucose infusion. Diabetes. 19: 302.

19. Blackard, W. G., and N. C. Nelson. 1971. Portal vein insulin concentrations in diabetic subjects. Diabetes. 20: 286.

20. Porte, D., Jr. 1969. Regulation of insulin secretion in vivo by glucose. In Progress in Endocrinology; Proceedings of the 3rd International Congress of Endocrinology. Mexico. C. Gual and F. J. G. Ebling, editors. Excerpta Medica Foundation, Publishers, Amsterdam. 192.

21. Christensen, N. J., and H. Orskov. 1968. The relationship between endogenous serum insulin concentration and glucose uptake in the forearm muscles of nondiabetics. J. Clin. Invest. 47: 1262.

22. Forbath, N., and G. Hetenyi, Jr. 1966. Glucose dynamics in normal subjects and diabetic patients before and after a glucose load. Diabetes. 15: 778.

23. Felig, P., and J. Wahren. 1971. Influence of endogenous insulin secretion on splanchnic glucose and amino acid metabolism in man. J. Clin. Invest. 50: 1702.

24. Bagdade, J. D., E. L. Bierman, and D. Porte, Jr. 1972. Counter regulation of basal insulin secretion during alcohol hypoglycemia in diabetic and normal subjects. Diabetes. 21: 65 . 